\title{
Implementation of Vertical Handoff Over LTE, Wi-Fi and WiMAX Networks
}

\author{
S. Neeraja, A. Abhishiktha
}

\begin{abstract}
The forthcoming wireless networks provide the continuous services to their users for different applications by the integration of diverse wireless access technologies known as heterogeneous wireless network. The heterogeneous wireless network improves the Quality of Service for stationary and non-stationary mobile users. Even when users are in mobility the services are provided by means of handoff or handover. In this paper, the integration of three different wireless networks such as LTE, WiMAX and Wi-Fi networks and their vertical handoff performance analysis are presented. These diverse wireless networks which are considered for integration are modeled as a heterogeneous wireless network. This network is designed using QualNet simulator. Furthermore, the designed heterogeneous network, vertical handoff performance is estimated by using factors such as throughput, jitter and End to End delay. With these performance factors, the designed network's Quality of Service $(Q o S)$ is estimated under mobility conditions.
\end{abstract}

Keywords: LTE, Quality of Service, Vertical Handoff, WiMAX.

\section{INTRODUCTION}

The Future generation wireless networks contain integration of different wireless networks in order to serve multiple users. Users access different wireless technologies such as Local Area Networks (LANs), wireless mesh networks and cellular networks based on their applications [1]. When the user is roaming one cell site to another cell site and it is shifted to another cell site known as handoff or handover. The handoff is occurred between the similar networks is termed as horizontal handoff and when the mobile node is moving randomly in different directions over different networks is termed as vertical handoff (VHO) or heterogeneous handoff [2]. One of the example for the heterogeneous wireless networks are fourth generation $(4 \mathrm{G})$ wireless networks.

Long Term Evolution network (LTE) and Worldwide Interoperability for Microwave Access (WiMAX) are the 4G wireless networks which can receive the signals from other networks and also provide universal coverage but Wi-Fi networks provides small coverage region. In order to cover large regions, the 4G LTE and WiMAX networks are considered. The 4G WiMAX is IEEE 802.16 standard which is developed in order to operate in both licensed and un

Revised Manuscript Received on December 13, 2019.

S. Neeraja*, Department of Electrical, Electronics and Communication Engineering, GITAM Deemed to be University, Visakhapatnam, India. Email: neeraja.sajja@gitam.edu

A. Abhishiktha, Department of Electrical, Electronic Communication Engineering, GITAM Deemed to be University, Visakhapatnam, India. Email: aremandaabhishiktha@gmail.com networks, the connection from the first cell site is terminated

licensed frequencies from $2 \mathrm{MHz}$ to $11 \mathrm{MHz}$ [3]. It is more flexible and it can provide the larger bandwidth up to $75 \mathrm{MHz}$ [4]. In 4G LTE is introduced in order to provide high data rates of $300 \mathrm{Mbps}$ for the down link and $75 \mathrm{Mbps}$ for the uplink. It can support the carrier bandwidth ranges from 1.4 $\mathrm{MHz}$ to $20 \mathrm{MHz}$ in both time division duplexing and frequency division duplexing. The connection between the all nodes in the network are IP based and the base station is termed as Evolved Node B (eNodeB) in the LTE network [5].

In general, the network users are served by the best access technologies, when the server need to provide the resources to the novel applications it offloads the part of $4 \mathrm{G}$ network traffic to the Wi-Fi network and provide the sources to the novel applications [6]. But the integration of multiple networks complicates the system design and performance assessment. It is overcome by accurately designing the mobility and traffic control model by using location updating, resource management and network planning. So, in this paper, the integration of LTE, Wi-Fi and WiMAX networks are designed using QualNet Simulator and their vertical handoff performance is examined by calculating the throughput, jitter and End to End delay (E - E Delay) which is helpful for practical situations.

In this paper, section I indicates the introduction to vertical handoff, LTE, Wi-Fi and WiMAX networks, section II describes the vertical handoff performance factors and implementation of vertical handoff among LTE, Wi-Fi and WiMAX by designing a heterogeneous wireless network scenario using QualNet under node mobility conditions during the simulation. Section III represents the results and discussion and finally section IV gives the conclusion.

\section{IMPLEMENTATION OF VERTICAL HANDOFF OVER LTE, WI-FI AND WIMAX NETWORKS}

The mobility models are classified as simulation model and analytical model. Analytical models generally limit client portability to a particular area inside the system where as the simulation models depend on continuous following of a client in periodic time steps [7]. Therefore, the objective of this work is to develop new simulation models for forthcoming wireless networks when the user is roaming among diverse networks using VHO. Generally, mobility of the mobile node between different networks affects the system performance and the QoS of the end user. For example, in $4 \mathrm{G}$ and Wi-Fi integrated model, the bandwidth provided to the mobile user may vary on order of magnitude due to allocation of bandwidth to newly connected mobile node after any VHO [8]. Hence, VHO should be perfectly modeled for the accurate design and performance evaluation of upcoming wireless technologies [9].

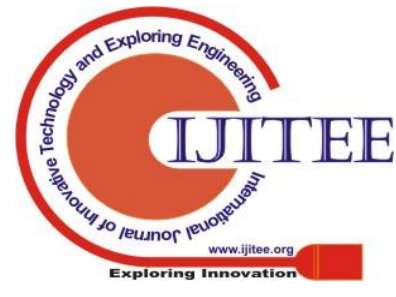




\section{Implementation of Vertical Handoff Over LTE, Wi-Fi and WiMAX Networks}

The key objective of this work is to design precise mobility models and vertical handoff performance analysis of LTE, Wi-Fi and WiMAX heterogeneous network.

The performance factors that are used to find the QoS of the designed network are throughput, E - E Delay and jitter [10]. Throughput is the ratio of amount of received data at the destination node $\left(\mathrm{N}_{\mathrm{d}}\right)$ to the time taken for the data to reach from the source node $\left(\mathrm{N}_{\mathrm{s}}\right)$ to the $\mathrm{N}_{\mathrm{d}}$ [11]. It is useful to find the rate at which the network successfully delivers the data from the $\mathrm{N}_{\mathrm{s}}$ to the $\mathrm{N}_{\mathrm{d}}$. Jitter gives the information about variation in delay by different data packets that may be reaching to the destination [12]. It is caused by different paths that are chosen by packets, jamming and other factors. It can seriously affect the quality of received data at the $\mathrm{N}_{\mathrm{d}}$. The packet's delay varied with respect to its location in the queues of the routers along the path between $\mathrm{N}_{\mathrm{s}}$ and $\mathrm{N}_{\mathrm{d}}$. E - E Delay indicates time taken for the packets to transfer from the $\mathrm{N}_{\mathrm{s}}$ to the application layer of $\mathrm{N}_{\mathrm{d}}$ [13]. This metric describes the packet delivery time, for better application performance the E - E Delay is minimum and vice versa.

To implement VHO, QualNet network simulator is considered. It is the one of the network simulators which provides graphical user interface (GUI) to configure vertical handoff scenarios in advanced wireless communication systems [14]. LTE, WiMAX and Wi-Fi heterogeneous wireless network scenario is designed by considering 23 nodes i.e. $\mathrm{N}_{1}$ to $\mathrm{N}_{23}$. Among these, $\mathrm{N}_{3}$ is acts as LTE base station, $\mathrm{N}_{13}$ acts as Wi-Fi network base station and $\mathrm{N}_{15}$ as WiMAX base station.

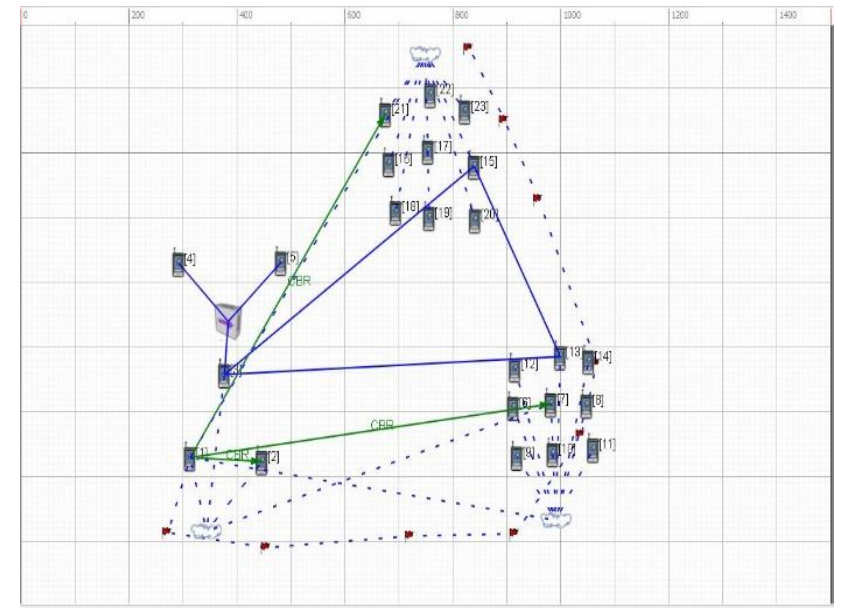

Fig. 1.Design of LTE, Wi-Fi and WiMAX heterogeneous network Scenario

Fig. 1 depicts the proposed scenario designed for vertical handoff between heterogeneous networks consisting of interconnection of LTE, Wi-Fi \& WiMAX under user mobility conditions. In LTE, all the connections between the devices are IP based whereas in WiMAX and Wi-Fi, the connections are based on MAC layer protocol. WiMAX is similar to $\mathrm{Wi}-\mathrm{Fi}$, except that it provides high-speed, broadband access at speeds similar to Digital Subscriber Line (DSL) and it can cover the several square miles using single WiMAX network.

In order to design LTE network, consider HUB for connecting the Gateways, Mobility Management Entity (MME), System Architecture Evolved (SAE) and eNodeB. In this scenario, $\mathrm{N}_{4}$ and $\mathrm{N}_{5}$ are act as MME and SAE, N3 is act as LTE eNodeB and $\mathrm{N}_{1}$ and $\mathrm{N}_{2}$ are the mobile nodes. The wireless sub connection is applied to the $\mathrm{N}_{1}, \mathrm{~N}_{2}$ and $\mathrm{N}_{3}$ which acts as the backbone network.

For designing the Wi-Fi network, consider nine mobile nodes $\left(\mathrm{N}_{6}\right.$ to $\left.\mathrm{N}_{14}\right)$ which are connected through the wireless subnet. Among these, $\mathrm{N}_{13}$ act as a base station 1 (BS1). In order to design the WiMAX network, consider nine mobile nodes $\left(\mathrm{N}_{15}\right.$ to $\left.\mathrm{N}_{23}\right)$ which are connected through the wireless subnet. Among these, $\mathrm{N}_{15}$ act as a base station 2 (BS2). The data traffic between these three networks are connected with CBR (Constant Bit Rate). CBR is applied to $\mathrm{N}_{1}$ to $\mathrm{N}_{7}, \mathrm{~N}_{1}$ to $\mathrm{N}_{2}$ and $\mathrm{N}_{1}$ to $\mathrm{N}_{21}$. Mobility is applied to the $\mathrm{N}_{1}$. In this scenario, Bellman Ford routing protocol is used for entire data connections for providing communication among all devices. Design parameters for vertical handoff is shown in Table 1.

Table- I: Design factors for LTE, Wi-Fi and WiMAX vertical handoff

\begin{tabular}{|l|l|}
\hline \multicolumn{1}{|c|}{ Parameter } & \multicolumn{1}{c|}{ Description } \\
\hline Channel type & Wireless Channel \\
\hline No. of Mobile Hubs & 1 \\
\hline No. of Mobile Wireless Subnets & 3 \\
\hline No. of Mobile Nodes & 23 \\
\hline Traffic Source & CBR \\
\hline Routing Protocol & Bellman Ford \\
\hline Antenna & Omni directional \\
\hline Time to Simulate & 300 Sec. \\
\hline Item size & $65000 \mathrm{bytes}$ \\
\hline
\end{tabular}

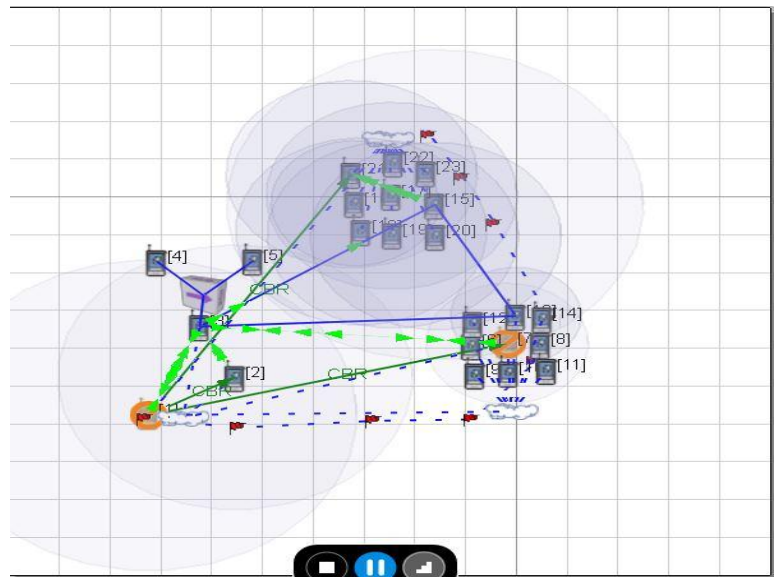

Fig. 2.Integration of LTE, Wi-Fi and WiMAX as a Heterogeneous network before vertical handoff

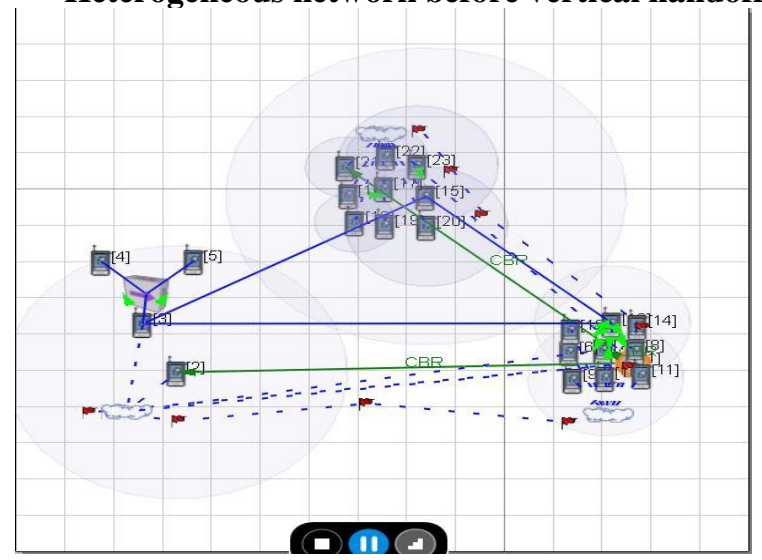

Fig. 3. Vertical handoff scenario between LTE and Wi-Fi heterogeneous network 


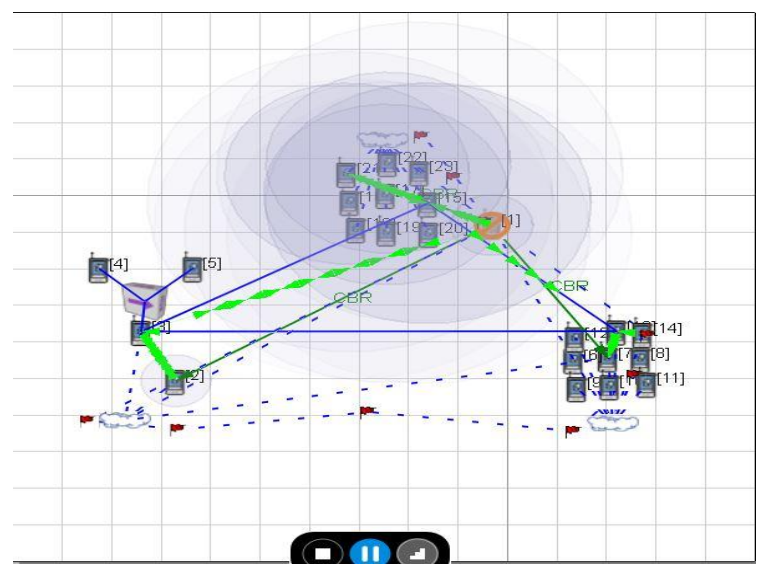

Fig. 4. Vertical handoff scenario between Wi-Fi and WiMAX heterogeneous network

From Fig. 2, it is observed that at the time of simulation starts from $\mathrm{N}_{1}$ which is initially connected to the eNodeB. Due to mobility, when the simulation is in progress $\mathrm{N}_{1}$ is move towards the Wi-Fi network at some point the connection between the $\mathrm{N}_{1}$ and $\mathrm{eNodeB}$ is terminated and new connection is established between $\mathrm{N}_{1}$ and $\mathrm{N}_{13}$ which is the Wi- Fi network base station as shown in Fig. 3. While progressing the simulation further $\mathrm{N}_{1}$ move out of Wi-Fi coverage region and move to words the WiMAX network at some point the connection between $\mathrm{N}_{1}$ and $\mathrm{N}_{7}$ is terminated and a new connection is established between $\mathrm{N}_{1}$ and $\mathrm{N}_{15}$ which is base station of WiMAX network it is observed in Fig. 4. It is clear that $\mathrm{N}_{\mathrm{s}}$ from one cell site is sending data to $\mathrm{N}_{\mathrm{d}}$ while roaming across different network environments. This simulation supports seamless mobility across heterogeneous networks by the vertical handoff process. The well-designed heterogeneous wireless network suitable for providing maximum throughput and jitter and E - E Delay values are minimum based on the transmitted data packets in practical conditions.

\section{SIMULATION RESULTS}

The simulation results show the total unicast messages sent and received when the vertical handoff is performed between LTE, WiMAX and Wi-Fi heterogeneous wireless networks and also observed the metrics for estimating the performance of the designed network such as throughput, jitter and E-E Delay.

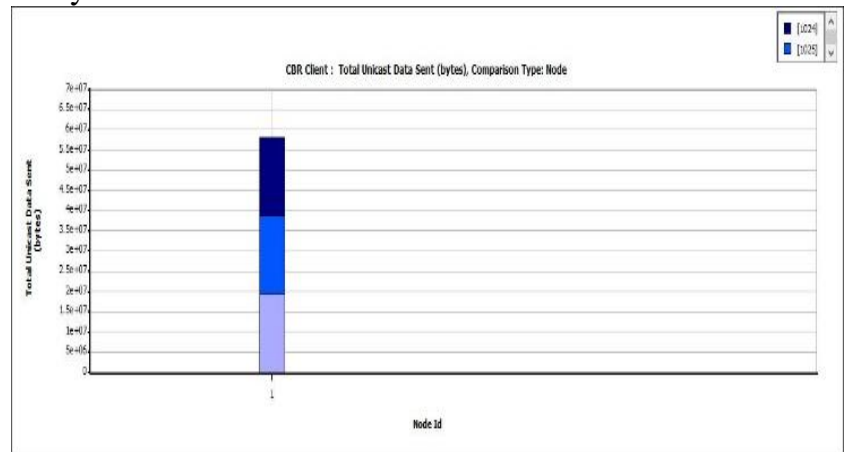

Fig. 5.Total Unicast Message Sent Vs Node Id

Fig. 5 gives the information about the total unicast information sent from the $\mathrm{N}_{\mathrm{s}}$ to the $\mathrm{N}_{\mathrm{d}}$. The total no. of data sent from the client is $5.85 \times 10^{7}$ bytes among this amount of data send from the node $\mathrm{N}_{1}$ to node $\mathrm{N}_{2}$ is $1.95 \times 10^{7}$ bytes, $\mathrm{N}_{1}$ to $\mathrm{N}_{7}$ is $1.95 \times 10^{7}$ bytes and from $\mathrm{N}_{1}$ to $\mathrm{N}_{21}$ is $1.95 \times 10^{7}$ bytes.

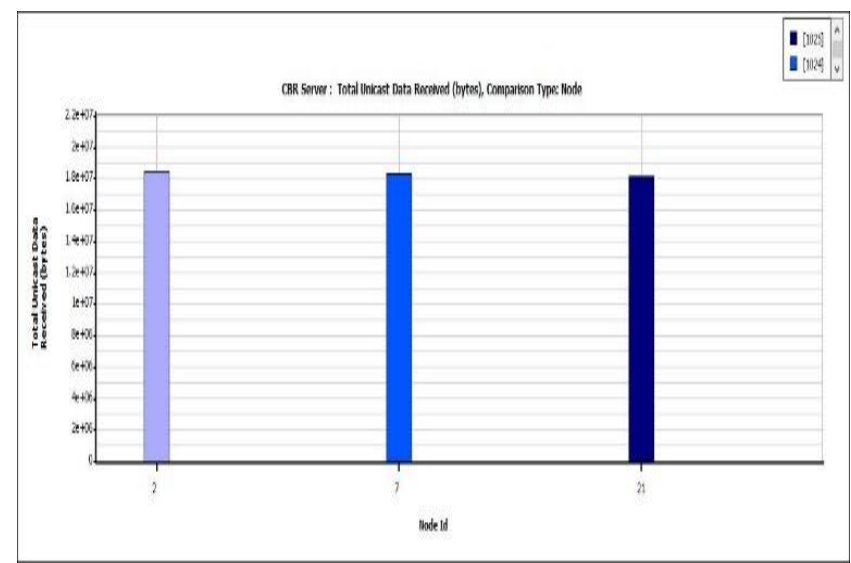

Fig. 6.Total Received Message Vs Node Id

From the Fig. 6, it is noticed that amount of data received at the destination. The amount of data that is received at the $\mathrm{N}_{2}$ is $1.8525 \times 10^{7}$ bytes at the $\mathrm{N}_{\mathrm{d}} \mathrm{N}_{7}$ is $1.8395 \times 10^{7}$ bytes and the data that is received at $\mathrm{N}_{21}$ is $1.82 \times 10^{7}$ bytes.

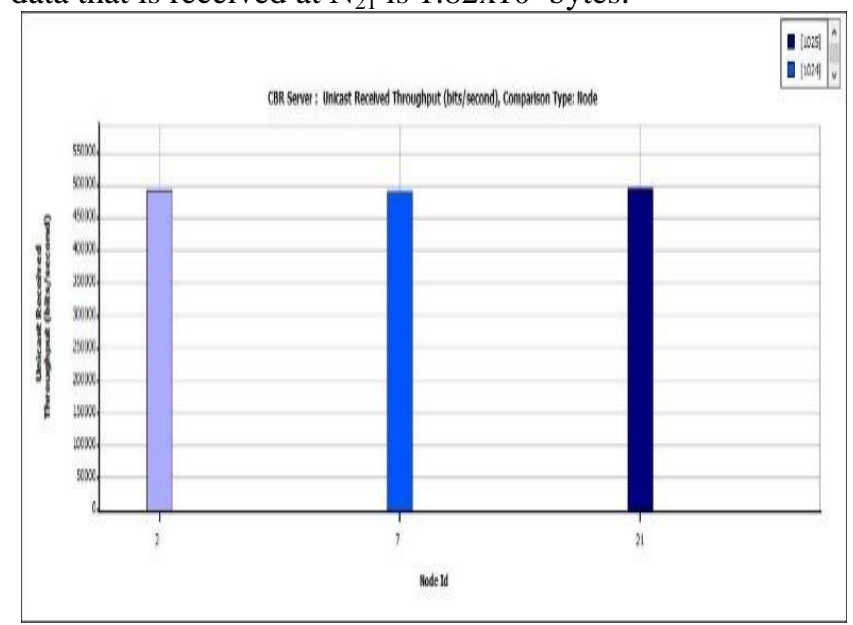

Fig. 7.Fig. 7 Received Throughput Vs Node Id

Fig. 7 describes about the average amount of data received at the destination during time interval. Due to vertical handoff, the average throughput at $\mathrm{N}_{\mathrm{d}} \mathrm{N}_{2}$ is 495778 bps at the $\mathrm{N}_{7}$, the throughput is $492386 \mathrm{bps}$ and at the $\mathrm{N}_{21}$ the throughput is 496471 bps.

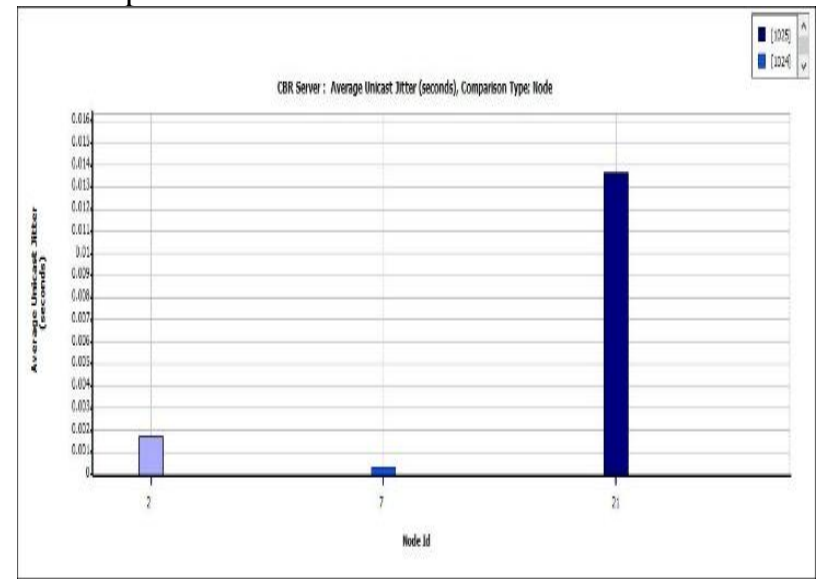

Fig. 8.Fig. 8 Average Unicast Jitter

Fig. 8 gives the information about average unicast jitter. Average Unicast Jitter at $\mathrm{N}_{\mathrm{d}} \mathrm{N}_{2}$ is $0.00178873 \mathrm{sec}$, at the $\mathrm{N}_{\mathrm{d}}$ $\mathrm{N}_{7}$ is $0.000382979 \mathrm{sec}$ and at the $\mathrm{N}_{21}$ the jitter value is $0.0136918 \mathrm{sec}$. Table 2 describes the performance factors of the designed vertical handoff scenario for heterogeneous wireless network (Integration of LTE, WiMAX and Wi-Fi).

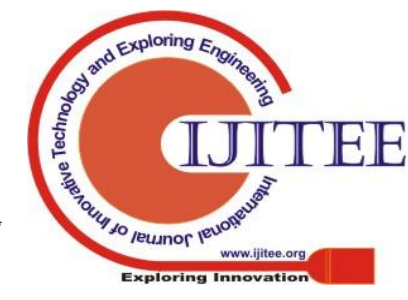




\section{Implementation of Vertical Handoff Over LTE, Wi-Fi and WiMAX Networks}

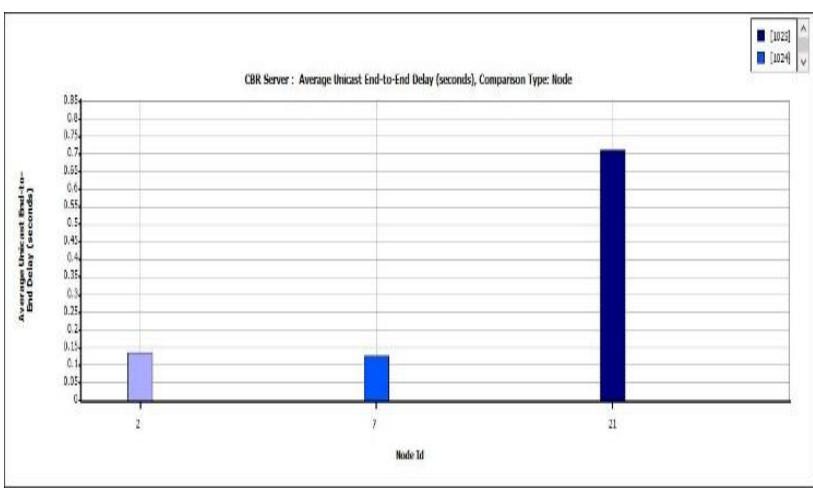

Fig. 9.Fig. 9 Average Unicast E - E Delay Vs Node Id

Fig. 9 illustrates the information about average unicast E - E Delay of the heterogeneous network. It gives the information about time taken for a packet to travel from the CBR source to the $\mathrm{N}_{\mathrm{d}}$ application layer. At $\mathrm{N}_{2} \mathrm{E}$ - E Delay is $0.137057 \mathrm{sec}$, at the $\mathrm{N}_{7} \mathrm{E}-\mathrm{E}$ Delay is $0.127936 \mathrm{sec}$ and at the $\mathrm{N}_{21}$ delay is

Table- II: Design factors for LTE, Wi-Fi and WiMAX vertical handoff

\begin{tabular}{|c|c|c|c|c|c|c|}
\hline \multicolumn{2}{|c|}{ CBR } & \multirow{2}{*}{$\begin{array}{c}\text { Data } \\
\text { sent } \\
\text { from } \\
\text { the } N_{s} \\
\text { (bytes } \\
\text { ) }\end{array}$} & \multirow{2}{*}{$\begin{array}{c}\text { Data } \\
\text { Receive } \\
\text { d } \\
\text { at } \mathbf{N}_{\mathbf{d}} \\
\text { (bytes) }\end{array}$} & \multicolumn{3}{|c|}{$\begin{array}{c}\text { VHO Performance } \\
\text { factors at } N_{d}\end{array}$} \\
\hline$N$ & $\begin{array}{l}N \\
d\end{array}$ & & & $\begin{array}{c}\text { Thro } \\
\text { ughp } \\
\text { ut } \\
\text { (bps) }\end{array}$ & $\begin{array}{c}\text { Jitter } \\
(\text { sec })\end{array}$ & $\begin{array}{c}E-E \\
\text { Delay } \\
(\text { sec })\end{array}$ \\
\hline \multirow[t]{3}{*}{1} & 2 & $\begin{array}{l}1.95 \mathrm{x} \\
10^{7}\end{array}$ & $\begin{array}{l}1.8525 x \\
10^{7}\end{array}$ & $\begin{array}{l}4957 \\
78\end{array}$ & $\begin{array}{l}0.0017 \\
887\end{array}$ & $\begin{array}{l}0.137 \\
057\end{array}$ \\
\hline & 7 & $\begin{array}{l}1.95 \mathrm{x} \\
10^{7}\end{array}$ & $\begin{array}{l}1.8395 x \\
10^{7}\end{array}$ & $\begin{array}{l}4923 \\
86\end{array}$ & $\begin{array}{l}0.0003 \\
829\end{array}$ & $\begin{array}{l}0.127 \\
936\end{array}$ \\
\hline & $\begin{array}{l}2 \\
1\end{array}$ & $\begin{array}{l}1.95 \mathrm{x} \\
10^{7}\end{array}$ & $1.82 \times 10$ & $\begin{array}{l}4964 \\
71\end{array}$ & $\begin{array}{l}0.0136 \\
918\end{array}$ & $\begin{array}{l}0.712 \\
706\end{array}$ \\
\hline
\end{tabular}

Table II shows the Performance factors of the designed vertical handoff scenario over LTE, Wi-Fi and WiMAX Networks. From the table it is observed that the designed network provides high throughput and less jitter and E - E Delay.

\section{CONCLUSION}

LTE, Wi-Fi and WiMAX heterogeneous wireless network is designed using QualNet 8.0 simulator. The mobility management of this network is analyzed by applying vertical handoff between LTE, Wi-Fi and WiMAX network. Under heterogeneous environment, using Bellman ford routing protocol, the vertical handoff performance is estimated by calculating throughput, E - E Delay and jitter. By transmitting $1.95 \times 10^{7}$ bytes of data from $\mathrm{N}_{1}$ to $\mathrm{N}_{2}$ with in the LTE network, at $\mathrm{N}_{2}$ throughput $495778 \mathrm{bps}$, jitter $0.00178873 \mathrm{sec}$ and $\mathrm{E}-\mathrm{E}$ Delay $0.137057 \mathrm{sec}$ are observed. Similarly, by transmitting the same amount of data from the $\mathrm{N}_{1}$ to $\mathrm{N}_{7}$ of Wi-Fi network and $\mathrm{N}_{1}$ to $\mathrm{N}_{21}$ of WiMAX network then the throughput is observed at $N_{7}$ is 492386 bps and at $N_{21}$ is 496471 bps. At these nodes, jitter and E - E Delay are also observed. From these observations, it is concluded that the designed LTE-Wi-Fi-WiMAX heterogeneous network provides the high throughput and less E - E Delay and jitter which is helpful for implementing $4 \mathrm{G}$ heterogeneous networks. $0.712706 \mathrm{sec}$.

\section{ACKNOWLEDGMENT}

This work was supported under Early Career Research Award by the SERB, Department of Science and Technology (DST), New Delhi, India (Grant no: ECR/2016/001804 dated: 13-FEB-2017). The authors would like to thank the management for encouraging towards research environment.

\section{REFERENCES}

1. De Schepper, Tom, et al. "ORCHESTRA: enabling inter-technology network management in heterogeneous wireless networks. "IEEE Transactions on Network and Service Management 15.4 (2018): 1733-1746.

2. Jin, Sunggeun, and Sunghyun Choi. "A seamless handoff with multiple radios in IEEE 802.11 WLANs." IEEE Transactions on Vehicular Technology 63.3 (2013): 1408-1418.

3. Fahoud, Amira Youssef, and D. K. Lobiyal. "Comparative analysis of WiMAX performance through mobility mode and fixed mode using qualnet simulator." International Conference on Computing, Communication \& Automation. IEEE, 2015.

4. Alotaibi, Youseef. "A performance analysis of different coding and modulation schemes in WiMAX." 2015 IEEE 10th Conference on Industrial Electronics and Applications (ICIEA). IEEE, 2015.

5. Guo, Tao, Atta ul Quddus, and Rahim Tafazolli. "Seamless handover for LTE macro-femto networks based on reactive data bicasting." IEEE Communications Letters 16.11 (2012): 1788-1791.

6. Ghosh, Amitava, et al. "LTE-advanced: next-generation wireless broadband technology." IEEE wireless communications 17.3 (2010): 10-22.

7. Wandra, K. H., Ketan Kotecha, and Mitul R. Khandhedia. "Various effect of modulation schemes on Wi-Fi network using qualnet simulator." 2010 2nd International Conference on Education Technology and Computer. Vol. 4. IEEE, 2010.

8. Agrawal, Ankur, Amutha Jeyakumar, and Neha Pareek. "Comparison between vertical handoff algorithms for heterogeneous wireless networks." 2016 International Conference on Communication and Signal Processing (ICCSP). IEEE, 2016.

9. Savitha, K., and C. Chandrasekar. "Comparison of vertical handoff decision scheme in heterogeneous wireless network." 2010 IEEE International Conference on Computational Intelligence and Computing Research. IEEE, 2010.

10. Moon, Ayaz Hassan, et al. "Simulating and analyzing security attacks in wireless sensor networks using QualNet." 2013 International Conference on Machine Intelligence and Research Advancement. IEEE, 2013.

11. Buratti, Chiara, and Roberto Verdone. "End-to-End Throughput of Ad Hoc Multi-Hop Networks in a Poisson Field of Interferers. " IEEE/ACM Transactions on Networking 25.5 (2017): 3189-3202.

12. Chitimalla, Divya, et al. "5G fronthaul-latency and jitter studies of CPRI over Ethernet." IEEE/OSA Journal of Optical Communications and Networking 9.2 (2017): 172-182.

13. Shahidi, Reza, and Mohamed Hossam Ahmed. "Probability distribution of end-to-end delay in a highway VANET." IEEE Communications letters 18.3 (2014): 443-446.

14. S. Neeraja, A. Abhishiktha. "Handoff Between LTE-LTE Networks using QualNet Simulator.'2019 International Journal of Innovative Technology and Exploring Engineering (IJITEE), Vol. 8.2019.

\section{AUTHORS PROFILE}

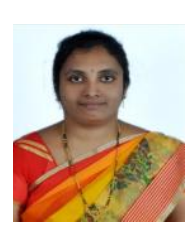

S. Neeraja is presently working as a Assistant Professo in the Department of Electrical, Electronics and Communications Engineering, GITAM (Deemed to be University). She received $\mathrm{Ph}$. D degree from Andhra university in the year 2013. She has over 13 years of Teaching Experience. She has published more than 30 research papers in various reputed International/National journals/Conferences. Her area of Interest is Wireless and Mobile Communications, Wireless Sensor Networks and CDMA/MIMO/OFDMA Wireless Communications. Currently, she is handling a DST-SERB research project.

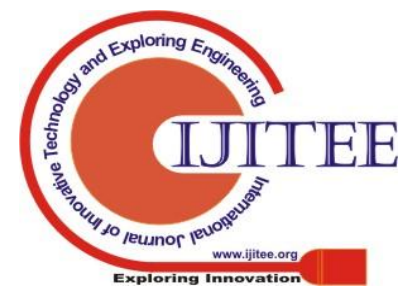


A. Abhishiktha is presently working as a SRF in the Department of Electrical, Electronics and Communications Engineering, GITAM (Deemed to be University) under DST-SERB research project. She has received the B. Tech degree from Vignan Nirula Engineering College and M.E from ANITS Engineering College, Visakhapatnam. Her areas of interests are Wireless Communications and Wireless Sensor Networks. 